\title{
Laboratorij za varstvo gozdov v letu 2018
}

\author{
Barbara PIŠKUR ${ }^{1 *}$, Nikica OGRIS, Andreja KAVČIČ, Maarten de GROOT, Špela JAGO- \\ DIC, Zina DEVETAK, Ana BRGLEZ, Simon ZIDAR, Dušan JURC
}

Laboratorij za varstvo gozdov (v nadaljevanu: LVG) Gozdarskega inštituta Slovenije predstavlja raziskovalno infrastrukturo slovenskega gozdarstva, ki omogoča temeljne in aplikativne raziskave povezane z zdravjem gozda ter nudi podporo strokovnemu delu pri reševanju aktualnih problemov s področja varstva gozdov in zdravstvenega varstva rastlin $\mathrm{v}$ gozdarstvu. LVG je infrastrukturna enota Oddelka za varstvo gozdov na Gozdarskem inštitutu Slovenije. V letu 2018 je bilo $\mathrm{v}$ oddelku devet zaposlenih, od tega pet doktorjev znanosti, mlada raziskovalka ter trije strokovni sodelavci (slika 1).

Poslanstvo LVG je identifikacija, preučevanje, spremljanje in napovedovanje gozdu škodljivih organizmov in abiotskih poškodb.

Laboratorij za varstvo gozdov Gozdarskega inštituta Slovenije je z odločbo UVHVVR na podlagi Zakona o zdravstvenem varstvu rastlin (ZZVR-1) pridobil javno pooblastilo za opravljanje nalog zdravstvenega varstva rastlin, med drugim tudi za izvajanje nalog diagnostičnih preiskav $\mathrm{v}$ skladu $\mathrm{z}$ ZZVR-1 in podrejenih predpisov.

Laboratorij za varstvo gozdov je trenutno nacionalni laboratorij za diagnostiko naslednjih karantenskih organizmov, reguliranih s seznami Direktive Sveta št. 2000/29/ES in odločbami oziroma sklepi Evropske komisije o nujnih ukrepih: Agrilus anxius, Agrilus planipennis, Agrilus auroguttatus, Atropellis spp., Dendrolimus sibiricus, Geosmithia morbida in njen vektor Pityophthorus juglandis, Monochamus spp., Fusarium circinatum, Pissodes spp., Polygraphus proximus, Xylosandrus crassiusculus, Anoplophora chinensis, Anoplophora glabripennis, Ceratocystis platani. Laboratorij za varstvo gozdov izvaja tudi diagnostiko vseh vzorcev s sumom na prisotnost neznanih vrst gliv in žuželk.

Laboratorij za varstvo gozdov je pooblaščen laboratorij za izdajanje rastlinskih potnih listov za seme rastlin Pinus sp. in Pseudotsuga sp.

Pri preučevanju škodljivih organizmov je bistvenega pomena dostop do referenčnega materiala in shranjevanje vzorcev kot dokaznega gradiva pri ponovnem preverjanju determinacij. V okviru LVG vzdržujemo Mikoteko in herbarij GIS (LJF), Zbirko živih kultur ZLVG in Entomološko zbirko. V okviru LVG vzdržujemo tudi informacijski sistem za beleženje in kartiranje gliv v Sloveniji Boletus informaticus ter elektronski informacijski sistem za varstov gozdov, ki ga sestavljaja javen spletni portal Varstvo gozdov (www.zdravgozd.si) in namizna aplikacija VG. Za evidentiranje vzorcev in analiz smo $\mathrm{v}$ okviru LVG razvili elektronski informacijski sistem LVG, katerega osrednji del je spletna aplikacija Zdravko.

Delo v Laboratoriju za varstvo gozdov pogojujejo nacionalni in evropski pravni okvirji zdravstvenega varstva rastlin in s področja gozdarstva.

Laboratorijska infrastruktura LVG bila tudi v letu 2018 pomembna pri izvajanju raziskav $\mathrm{v}$ okviru naslednjih projektov in programov:

- COST FP1403: Non-native tree species for european forests - experiences, risks and opportunities (NNEXT)
- COST FP1401: A global network of nurseries as early warning system against alien tree pests (Global warning)

- COST FP1406: Pine pitch canker - strategies for management of Gibberella ircinata in greenhouses and forests (PINESTRENGTH)

- COST TD1209: European Information System for Alien species (ALIEN CHALLENGE)

- COST FP1102: Determining Invasiveness And Risk Of Dothistroma (DIAROD)

- COST CA17122: Increasing understanding of alien species through citizen science (Alien-CSI)

- Awareness Raising, Training and Measures on Invasive alien Species in forests (LIFE ARTEMIS)

- Mehanizmi odpornosti za tveganjem prilagojeno gospodarjenje $\mathrm{z}$ gozdovi $\mathrm{v}$ pogojih klimatskih sprememb, $\mathrm{v}$ okviru iniciative ERA-NET SUMFOREST

- Programska skupina P4-0107: Gozdna biologija, ekologija in tehnologija (1.1.2015-31.12.2019, vodja: H. Kraigher)

- Obratovalni monitoring na osrednjem vadišču slovenske vojske (OSVAD) (2016-2019, M. de Groot)

- CRP V4-1623: Razvoj metod zaznavanja poškodb iglavcev zaradi smrekovih in jelovih podlubnikov ter izdelava modelov za napovedovanje namnožitev smrekovih in jelovih podlubnikov v slovenskih razmerah (2018-2021, vodja N. Ogris)

V LVG izvajamo analize vzorcev, ki jih pridobimo v okviru Javne gozdarske službe (nalogi JGS 2A in 2B) in v okviru javnega pooblastila za izvajanje nalog zdravstvenega varstva rastlin (UVHVVR). V letu 2018 smo v okviru Javnega pooblastila pregledali 579 vzorcev (od tega so 28 vzorcev posredovali inšpektorji Inšpekcije za varno hrano, veterinarstvo in varstvo rastlinUVHVVR) in naredili 621 analiz. V okviru naloge JGS2B smo pregledali 32 vzorcev, v okviru naloge JGS 2A pa 43 vzorcev. V letu 2018 smo v Herbarij in mikoteko GIS vnesli 906 vzorcev.

Poleg raziskovalnega dela $\mathrm{v}$ okviru tekočih projektov in programov ter diagnostičnih storitev, je LVG v letu 2018 nudil infrastrukturno podporo pri svetovanju in izdajanju strokovnih mnenj s področja varstva rastlin. V LVG potekajo tudi raziskave v okviru doktorskih nalog (mlada raziskovalka Ana Brglez, doktorski kandidat Dušan Sadiković), diplomskih na$\log$ (študentki gozdarstva Lea Hrastovšek in Maruša Urevc) in raziskovalnih nalog (študent biotehnologije Andraž Marinč).

V letu 2018 smo raziskovalno in strokovno sodelovali z Univerzo v Padovi (Italija), FABI (Južna Afrika), Univerzo v Zagrebu (Hrvaška), BFW (Avstrija), Univerzo v Ljubljani (Slovenija), NIB (Slovenija), KIS (Slovenija), ZGS (Slovenija), SiDG (Slovenija), fitosanitarno in gozdarsko inšpekcijo, ANSES (Francija).

V letu 2019 bo delo $v$ LVG predvidoma potekalo v enakem obsegu kot v 2018, poleg aktivnosti v okviru tekočih nalog bomo nadaljevali z osnovnim raziskovanjem gliv Eutypella

\footnotetext{
${ }^{1}$ Gozdarski inštitut Slovenije, Večna pot 2, 1000 Ljubljana *barbara.piskur@gozdis.si
} 
parasitica, Lecanosticta acicola, Pseudodidymella fagi ter ambrozijskih podlubnikov. V letu 2019 predvidevamo širitev laboratorijskih prostorov ter posodobitev laboratorijske infrastrukture. Konec marca 2019 se bo upokojil D. Jurc, zaposlil pa se bo gozdar Peter Smolnikar. Za večjo varnost dela s karantenskimi žuželkami predvidevamo premestitev entomološkega dela laboratorija v laboratorijske kontejnerje. V letu 2019 želimo pričeti s postopkom akreditacije po standardu SIST ISO 17025:2017. Če povzamemo, Laboratorij za varstvo gozdov bo tudi v 2019 deloval kakovostno in korektno.

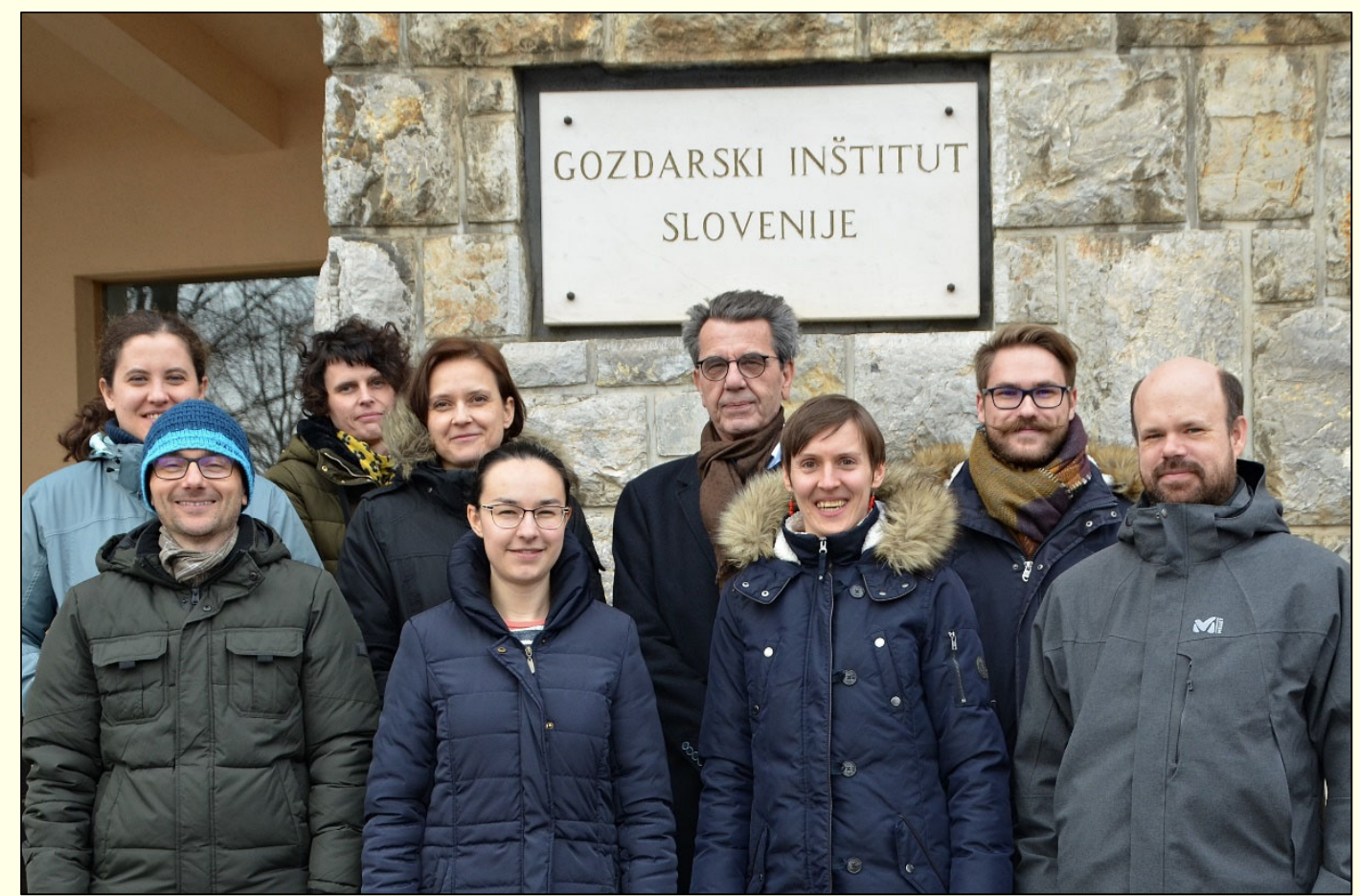

Slika 1: Sodelavke in sodelavci Laboratorija za varstvo gozdov (od leve): Zina Devetak, Nikica Ogris, Barbara Piškur, Špela Jagodic, Ana Brglez, Dušan Jurc, Andreja Kavčič, Simon Zidar, Maarten de Groot (foto: Simon Zidar) 